Brumatti, P.N.; Santana, C.M.; Dantas, F.R.; Marques-Junior, S. Percepção de estudantes quanto aos impactos na criação e visitação de parques naturais protegidos. Revista Brasileira de Ecoturismo, São Paulo, v.11, n.4, ago2018/jan2019, pp.673694.

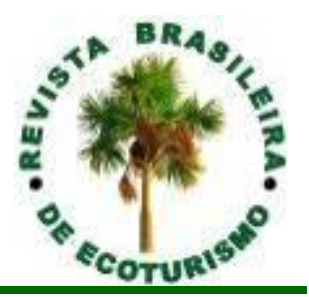

\title{
Percepção de estudantes quanto aos impactos na criação e visitação de parques naturais protegidos
}

\section{Perception of students as to the impact on creation and visitation of protected natural parks}

\author{
Paula Normandia Brumatti, Carla Medeiros Santana, \\ Fernanda Raphaela Dantas, Sérgio Marques Junior
}

\begin{abstract}
RESUMO: O objetivo do presente artigo é investigar os impactos ambientais, econômicos e sociais associados ao apoio à criação e visitação de áreas naturais protegidas, como os parques naturais, realizado com alunos de graduação em turismo do Estado do Rio Grande do Norte. Neste sentido, foi feita uma pesquisa quantitativa descritiva, com amostragem não probabilística, aplicada a 111 alunos de graduação em turismo nas instituições IFRN e UFRN. O instrumento de pesquisa consistiu em um questionário elaborado e aplicado no mês de maio de 2017, no qual continha 39 assertivas sobre o tema proposto a serem respondidas de acordo com o grau de concordância em escala métrica de 11 pontos. Utilizou-se o Software SPSS versão 22.0/2013 para o tratamento e análise dos dados. A análise fatorial foi realizada com o objetivo reduzir variáveis e construir um conjunto que explicasse as determinadas dimensões. Os resultados demonstraram um significativo apoio à criação de parques naturais protegidos pelo público de estudantes, associado aos possíveis impactos positivos ambientais, sociais e econômicos. Acredita-se que estudos que contemplem outros públicos como residentes e gestores dos parques podem contribuir para uma melhor compreensão do apoio a criação destas áreas e os impactos relacionados a este processo e ao uso público das mesmas.
\end{abstract}

PALAVRAS-CHAVE: Turismo; Áreas Protegidas; Impactos; Análise Fatorial.

ABSTRACT: The objective of this article is to investigate the environmental, economic and social impacts associated to the support of protected areas creation and visitation, such as natural parks, carried out with undergraduate tourism students of Rio Grande do Norte State, in Brazil. In this sense, a descriptive quantitative research, with non-probabilistic sampling, was applied to 111 students from two different education institutions, IFRN and UFRN. The research instrument consisted of a questionnaire with 39 assertions related to the subject, to be answered according to the degree of agreement based on an 11-point scale. The questionnaire was elaborated and applied in May 2017. For data reduction and analysis, the SPSS for Windows- version 22.0 / 2013, was conducted. The factor analysis was performed with the objective of reducing variables and constructing a set to explain the given dimensions. The results showed a significant students' support to the creation of protected natural parks, associated with possible positive environmental, social and economic impacts. It is expected that researches involving other audiences as residents and managers of the parks may contribute to a better understanding of the support issues related to the creation of a protected area, as well the impacts associated to this process and the public use of them.

KEYWORDS: Tourism; Protected Areas; Impacts; Factor Analysis.

Sociedade Brasileira de Ecoturismo. Rua Dona Ana, 138, Vila Mariana, São Paulo, SP - Brasil.

E-mail: rbecotur@sbecotur.org.br; Tel. (55-11) 99195-7685. 


\section{Introdução}

O contexto pós-industrial, de intensa urbanização, crescimento populacional e uso inadequado dos recursos naturais passa a exigir a adoção de medidas de proteção do patrimônio ambiental nas mais diversas regiões do mundo. Já no final do século XIX, a partir de uma ideologia protecionista dos recursos naturais, países como os Estados Unidos e Canadá iniciam a criação de áreas protegidas, os parques nacionais (DIEGUES, 2000). Naquele momento, basearam-se em critérios estéticos delimitando áreas consideradas "selvagens", as quais mantinham seus atributos naturais pouco modificados pelo homem.

Já no século XX e a partir da Segunda Guerra Mundial, o desejo de evasão, descanso e recreação em ambientes próximos à natureza é intensificado, isto posto pelo crescimento das cidades e conglomerados urbanos, dos novos sistemas de transportes e consequentemente da expansão do turismo. Segundo Pacheco e Raimundo (2014), no Brasil, a redemocratização asseverou as disputas entre o público e o privado e entre a propriedade particular e bem comum, ou coletivo. Neste sentido, principalmente os parques em áreas urbanas, passaram a constituir um dos principais instrumentos das "novas" políticas urbanas e de reivindicação de direitos coletivos, que utilizaram como principais argumentos para criação e/ou manutenção destas áreas os serviços ambientais que estas prestam à sociedade.

Segundo Ruschmann (2001, p.15), uma maior sensibilidade ambiental e social e "o crescimento da demanda e, consequentemente, da oferta turística, e as facilidades para as viagens tornaram o mundo inteiro acessível aos viajantes ávidos por novas e emocionantes experiências em regiões com recursos naturais e culturais consideráveis". Neste contexto, ganham destaque as atividades turísticas realizadas em ambientes naturais preservados e, principalmente, em áreas naturais protegidas, como os parques nacionais.

O governo brasileiro passa a considerar o ecoturismo uma atividade estratégica capaz de gerar empregos, capacitação profissional e distribuição de renda às populações que habitam o entorno das áreas protegidas (BRASIL, 2010). Assim como na contribuição de atividades de educação ambiental, isto por causa da interação entre turistas e natureza, colaborando com o reconhecimento do patrimônio ambiental.

Assim, através do Sistema Nacional de Unidades de Conservação da Natureza - SNUC, Lei n. 9.985 do ano de 2000, o Ministério do Meio Ambiente institui as Unidades de Conservação e define um conjunto de diretrizes e procedimentos oficiais que possibilitam às esferas governamentais federal, estadual e municipal e à iniciativa privada, a criação, implantação e gestão de Unidades de Conservação (UC), sistematizando assim a preservação ambiental no país (BRASIL, 2000).

Atualmente, o SNUC (BRASIL, 2000) apresenta entre suas 12 categorias, os Parques Nacionais como áreas que incentivam a visitação e o uso turístico das mesmas. Dos objetivos de conservação destacados pelo 
Ministério do Meio Ambiente relacionados ao uso público das unidades de conservação pelo turismo tem-se "favorecer condições e promover a educação e interpretação ambiental, a recreação em contato com a natureza e o turismo ecológico" (BRASIL, 2000).

No entanto, as questões de uso para a visitação e para o turismo, com seu caráter multifacetado, perpassam por discussões e debates acerca das possibilidades de impactos, positivos ou negativos, advindos dessas práticas nas mais variadas dimensões, econômica, social, cultural e ambiental, sendo assim pertinente a perspectiva de planejamento e gestão adequados a essas áreas (PIRES, 2006).

Nesse sentido, têm sido elaboradas metodologias para identificação dos impactos causados pela criação e visitação nas áreas naturais protegidas nas diferentes dimensões e abordagens. A World Wildlife Fund - WWF e o Instituto de Educação Brasil - IEB criaram um método de Avaliação dos Impactos Sociais de Áreas Naturais Protegidas no Brasil, com o objetivo voltado principalmente para a contribuição no planejamento e gestão desses espaços, na perspectiva de garantir que as UCs sejam instrumentos que auxiliem na conservação da biodiversidade, bem como, na promoção do desenvolvimento sustentável das populações que vivem no entorno ou interior das áreas, para a promoção de alguns aspectos relacionados à qualidade de vida.

Sendo assim, o presente artigo pretende investigar entre estudantes do ensino superior, curso de turismo, no Estado do Rio Grande do Norte - RN, o imaginário por trás da ideia sobre a criação e visitação dos parques como unidades de conservação, urbanos ou não, e as possíveis implicações envolvidas neste processo.

A análise do imaginário, neste estudo, se dará por meio da avaliação da percepção sobre os parques e seus possíveis impactos, como áreas protegidas, a partir da leitura sobre seu conceito e objetivos como consta na lei do SNUC, ou seja, considerando o entendimento, a interpretação e o julgamento daquilo que foi exposto textualmente, porém admitindo que alguma experiência individual também participa deste processo de construção do imaginário das pessoas.

Acredita-se que estudos de percepção sobre unidades de conservação podem contribuir para elucidar possíveis interpretações acerca das funções socioambientais dos parques e identificação dos aspectos positivos e negativos associados à criação e visitação destas áreas, assim como, facilitar a comunicação entre visitantes, gestores e comunidades envolvidas com a área e a gestão destes espaços sociais.

Objetivou-se, assim, investigar quais os impactos ambientais, econômicos e sociais se associam à ideia de apoio à criação e visitação de áreas naturais protegidas, mais especificamente da categoria de Parques, na visão de graduandos dos cursos de turismo do IFRN e UFRN. 


\section{Contextualização histórica e conceptiva dos parques}

A criação de áreas protegidas se deu inicialmente com o objetivo de preservar o cenário paisagístico de um determinado território. No entanto, na atualidade, em virtude da escassez dos recursos naturais e da perda da biodiversidade em escala mundial, a criação destas áreas passa a representar uma importante ferramenta de conservação do patrimônio ambiental para as gerações atuais e futuras.

Relatos históricos registram que as primeiras experiências de delimitação de áreas com o objetivo de preservar ambientes naturais, atividades como a caça, e/ou espécies, remete-se à Antiguidade. Tem-se registros sobre parques naturais, "na Mesopotâmia, regiões da Assíria e Babilônia, possivelmente em decorrência da situação de escassez das populações animais" (BENNETT apud VALLEJO, 2002, p.2). No ocidente, essa configuração, versa sobre a Idade Média, quando havia o destino de áreas para a utilização exclusiva da sociedade feudal e para o reduto de algumas espécies por ordem dos reis (ROCHA, 2002). Porém, nenhum desses registros remete-se a utilização dessas áreas de maneira pública ou voltada ao lazer.

Com a revolução industrial e o crescimento da população urbana e fabril, surgem novas demandas por espaços públicos e para o lazer. Ruschmann (2001) afirma que a preocupação com o meio ambiente se deu a partir dos centros urbanos, devido ao avanço desenfreado da "produção suja", conduzindo a humanidade a uma perda na qualidade de vida e destruição das condições de sobrevivência em certos lugares.

Neste sentido, a proteção de áreas naturais, principalmente na forma de parques, com a intenção de conservar o ambiente, promover a qualidade de vida às populações ocidentais e um contato mais próximo com a natureza, tornou-se relevante e crescente (PUREZA; PELLIN; PADUA, 2015). Do fim do século XIX até a década de 1980, os parques foram considerados a forma mais clara e clássica para designar áreas que garantissem a proteção dos ecossistemas e permitissem uma maior aproximação do homem urbano com a natureza, através de atividades de lazer e de turismo (DOUROJEANNI, 2015).

Assim, o símbolo basilar dessa concepção de áreas protegidas fica estabelecido com o surgimento do Parque Nacional de Yellowstone nos Estados Unidos da América - EUA em 1872, que tinha como perspectiva a noção de "Wilderness" (vida natural selvagem) com a característica de áreas não povoadas, mas com fins de recreação para a população urbana ocidental (DIEGUES, 2000). A ideia inicial, que prevalecia neste modelo, considerava o homem dissociado do espaço natural, ou seja, em áreas destinadas a preservação ambiental, como os parques naturais, não poderia existir a residência humana, motivo pelo qual os indígenas foram expulsos de suas terras. 
Tradicionalmente, os PNs eram concebidos, sobretudo, para proveito limitado do homem urbano e para a conservação dos recursos para as futuras gerações, não se admitindo no seu interior a presença humana permanente, nem a posse particular das terras, nem a exploração dos recursos naturais. Essa concepção baseava-se no preceito segundo o qual os humanos seriam modificadores ou destruidores contumazes de seu ambiente natural e, portanto, a conservação da natureza requereria a criação de áreas livres de sua presença (ROCHA; DRUMMOND; GANEM, 2010, p.209).

O modelo americano preservacionista foi reproduzido em outros países, como Nova Zelândia, Canadá, Austrália e África do Sul (DIEGUES, 2000), pois, como todos sofriam com relevantes danos ao meio ambiente, viase a oportunidade de introduzir esta ideia como solução aos problemas ambientais (QUINTÃO apud BRITO, 2000). "A partir dos anos 50, mas especialmente na década de 70, o mundo conheceu uma impressionante expansão do estabelecimento de áreas naturais protegidas: 1.300 novos parques foram criados" (BRITO, 2000, p.27).

No Brasil, esse processo de estabelecimento e criação de áreas naturais protegidas, teve início em 1937, com o Parque Nacional de Itatiaia, e assim como outros países, também utilizou o modelo de parque de Yellowstone. Isto se deu quando o país começou a experimentar um crescimento urbano acelerado e uma ampla industrialização, o que fez com que houvesse um maior interesse em delimitar áreas voltadas à conservação ambiental e proteção cênica. De acordo com Rocha et. al (2010), o Brasil criou no período de 1937 a 2008, 65 parques nacionais, sem considerar os parques estaduais e municipais.

Porém, esse modelo rígido e excludente e a ideia de ruptura entre homem e meio ambiente, presentes nas iniciais concepções de parques naturais, resultou na geração de inúmeros conflitos. Assim, no III Congresso Mundial de Parques Nacionais, da União Internacional de Conservação da Natureza (UICN), em 1982, novas orientações são enfatizadas quanto ao manejo integrado dessas áreas com as comunidades originais, o que colaboraria para inserção dos parques no desenvolvimento regional e melhoria da qualidade de vida destas populações (ROCHA et al., 2010).

Tornou-se necessária a definição de um único conceito de áreas protegidas, considerando a perspectiva de preservação da natureza adequada às realidades de cada país, o direito de uso dessas áreas de preservação por grupos étnicos e a construção de diretrizes para criação e gestão de áreas de proteção ambiental.

Neste contexto, em 1994 a UICN definiu área natural protegida como "uma superfície de terra ou mar consagrada à proteção e manutenção da diversidade biológica, assim como dos recursos naturais e dos recursos culturais associados e manejados através de meios jurídicos e outros eficazes" (UICN apud BRITO, 2000, p.19). 
Nesta perspectiva, é instituído o Sistema Nacional de Unidades de Conservação (SNUC), Lei n. 99.985 no ano de 2000, no qual novas categorias de manejo distintas são criadas e divididas em dois grupos: as Unidades de Proteção Integral, o caso dos parques, admitindo apenas o uso indireto dos seus recursos naturais, como atividades educacionais, recreativas e turísticas; e as Unidades de Uso Sustentável, nas quais é permitido o uso direto dos recursos naturais em consonância à garantia dos processos ecológicos e da manutenção da biodiversidade (BRASIL, 2011a). Assim, o Brasil manteve a sua posição quanto a restrição de populações nas áreas de parque, garantindo apenas a possibilidade de estudos técnicos e a abertura para consultas públicas para sua criação e implantação.

De acordo com o SNUC, em seu Art. 11,

O Parque Nacional tem como objetivo básico a preservação de ecossistemas naturais de grande relevância ecológica e beleza cênica, possibilitando a realização de pesquisas científicas e o desenvolvimento de atividades de educação e interpretação ambiental, de recreação em contato com a natureza e de turismo ecológico.

$\S 1^{\circ}$ O Parque Nacional é de posse e domínio públicos, sendo que as áreas particulares incluídas em seus limites serão desapropriadas, de acordo com o que dispõe a lei.

$\S 2^{\circ} \mathrm{A}$ visitação pública está sujeita às normas e restrições estabelecidas no Plano de Manejo da unidade, às normas estabelecidas pelo órgão responsável por sua administração, e àquelas previstas em regulamento.

$\S$ 3으 A pesquisa científica depende de autorização prévia do órgão responsável pela administração da unidade e está sujeita às condições e restrições por este estabelecidas, bem como àquelas previstas em regulamento.

$\S 4^{\circ}$ As unidades dessa categoria, quando criadas pelo Estado ou Município, serão denominadas, respectivamente, Parque Estadual e Parque Natural Municipal (BRASIL, 2000).

Com base na Lei, evidencia-se que cabe às áreas de parques, a preservação dos ecossistemas conjugada às atividades de pesquisas, de recreação e de educação ambiental. $E$ que, portanto, deveriam servir a assegurar a "aproximação com a natureza", bem como, o direito constitucional do acesso ao lazer, que somente será possível por meio de

um conjunto de atividades e de equipamentos combinados, que sirvam à população frequentadora desses parques e que sejam capazes de provocar mudanças nas atitudes dos sujeitos sobre a natureza e sobre a própria cidade, em seu momento de lazer (PACHECO; RAIMUNDO, 2014, p.53). 
Desta forma, embora os parques ainda representem espaços passíveis de segregação e exclusão social. O turismo nestas áreas de proteção vem ganhando destaque no cenário nacional, estadual e municipal, visto como potencial gerador de renda para subsidiar a administração e gestão da própria unidade e seus recursos e, consequentemente, fomentar estruturas e equipamentos para a prática de atividades de lazer programadas tanto aos turistas quanto aos residentes, colaborando para a melhoria da qualidade de vida.

De acordo com uma pesquisa divulgada pelo Ministério do Meio Ambiente (BRASIL, 2016) houve um crescimento de $238 \%$ nas visitações em Parques Nacionais passando de 2,9 milhões em 2007 para 7,1 milhões em 2015. No entanto, os próprios ministérios do turismo e do meio ambiente reconhecem que o desafio consiste em desenvolver um turismo e uma visitação responsável, integrados à diversidade sociocultural, aos conhecimentos tradicionais e à conservação da biodiversidade.

\section{Unidades de Conservação, turismo e impactos}

O turismo é apresentado no contexto das unidades de conservação, principalmente dos parques, como um colaborador na gestão e desenvolvimento desses espaços que, apesar de possuírem como principal objetivo a conservação de recursos naturais e a biodiversidade, também se constituem em possibilidade de melhor desenvolvimento socioeconômico, qualidade de vida e valorização da cultura local.

A relação existente entre turismo e meio ambiente é explicita e inegável, já que, com o conglomerado nos grandes centros urbanos o contato com natureza é uma das maiores motivações de lazer dos turistas. Porém, nos lugares onde o fluxo de pessoas é massivo e onde os atrativos naturais se constituem bases para o desenvolvimento do turismo, é relevante considerar os possíveis efeitos negativos derivados dessa atividade. O uso de ambientes frágeis pelo turismo requer um conjunto de medidas capazes de garantir a qualidade ambiental e a conservação dos recursos naturais para garantir então continuidade de seu uso de forma racional (RUSCHMANN, 2001; ROCKTAESCHEL, 2006).

Os benefícios ao meio ambiente através do uso público pelo turismo destacam-se pela capacidade de planejamento e ordenamento da atividade na exploração dos recursos naturais, levando ao aproveitamento mais racional destes recursos e a fruição do patrimônio natural e cultural. Além disso, outra contribuição pode derivar do aumento da sensibilização ambiental e do consumo mais sustentável por meio da rede de distribuição de serviços. Ressalta-se ainda, que a chegada do turismo e a presença de visitantes/ turistas pressionam as autoridades locais a adotar medidas de planejamento e gestão para proteção ambiental (PIRES, 2006; OLIVEIRA, 2008).

Apesar dos riscos da atividade turística praticada em ambientes naturais, ainda assim, de forma específica, em unidades de conservação e em Parques, o SNUC (2000) enfatiza a importância do turismo ecológico para esses espaços. O governo (2011a, p.8) ainda acrescenta que a visitação em 
unidades de conservação é uma forma de aproximar a sociedade e despertar o interesse em conservação da natureza, considerando a possibilidade de contato e recreação com o ambiente natural, e que:

\begin{abstract}
O turismo é capaz de dinamizar as economias locais e incrementar os recursos financeiros para manutenção de unidades de conservação. O grande desafio, no entanto, é desenvolver o turismo responsável e integrado a diversidade sociocultural, aos conhecimentos tradicionais e a conservação da biodiversidade (BRASIL, 2000, p.8).
\end{abstract}

De acordo com Faraji e Aghajani (2010), o turismo contribui com áreas naturais protegidas, pois, além da atração de visitantes e do reforço aos recursos naturais como valiosos e da questão do aumento da sensibilização ambiental como afirmam autores já citados. Também, segundo essas autoras, o turismo traz contribuição financeira direta com as taxas de entradas dos parques, sendo coletadas de visitantes, turistas ou operadores turísticos, recurso este que pode auxiliar na proteção e gestão dessas áreas.

Tendo como esforço promover o turismo em unidades de conservação, o Ministério do Turismo junto com o Plano Nacional de Turismo (PNT) (BRASIL, 2011b) definiu algumas metas para a atividade em território nacional para os anos de 2014, 2018 e 2022, onde tem-se a finalidade estimular um turismo responsável e o desenvolvimento territorial nas áreas naturais protegidas e seu entorno, neste documento são descritos a importância da atividade turística em áreas naturais, assim como é distribuído os impactos que cada setor precisará passar para a viabilização dessas metas.

No setor econômico, o incremento na competitividade, o aumento de receitas das atividades do turismo, um maior volume de arrecadação de impostos, o crescimento do PIB, os efeitos sinérgicos, entre outros, foram os fixados. Já para o setor ambiental, pensa-se que um crescimento mais ordenado, a preservação do patrimônio natural, a qualidade das cidades, o combate à especulação imobiliária e a favelização, entre outros, são os que merecem ser solucionados. Por fim, no setor social, a geração de empregos, a elevação do nível cultural da população, a desconcentração do desenvolvimento, etc., foram os gargalos definidos pelo PNT (BRASIL, 2011b).

Salvo esses impactos que foram identificados pelo PNT (BRASIL, 2011b) como dificuldades que precisam ser sanadas para um melhor crescimento do turismo em áreas protegidas, ainda tem os impactos negativos do turismo sobre o meio ambiente definido por Pires (2006). Segundo este autor, esses efeitos podem acontecer sobre os componentes básicos.

De acordo com o PNT a visitação em unidades de conservação é uma forma de aproximar a sociedade e despertar o interesse em conservação da 
natureza, considerando a possibilidade de contato e recreação com o ambiente natural.

\begin{abstract}
O turismo é capaz de dinamizar as economias locais e incrementar os recursos financeiros para manutenção de unidades de conservação. O grande desafio, no entanto, é desenvolver o turismo responsável e integrado a diversidade sociocultural, aos conhecimentos tradicionais e a conservação da biodiversidade (BRASIL, 2011a, p.8).
\end{abstract}

De acordo com Faraji e Aghajani (2010), o turismo contribui com áreas naturais protegidas, pois, além de atrair visitantes para o reconhecimento do patrimônio ambiental ele é capaz de agregar valor aos recursos naturais (e.g fauna, flora, recursos hídrico e geomorfológicos), através de serviços (e.g recreativas e esportivas) e da integração com valores da cultura local (e.g uso e significados dos recursos por populações tradicionais), contribuindo para a sensibilização do público quanto a importância de conservação deste patrimônio socioambiental.

Através do provimento de serviços e algumas atividades do lazer, a visitação também pode contribuir financeiramente para a conservação, manutenção e gestão dos parques, isto de maneira direta (taxas de entrada, permanência) ou indireta, por meio dos serviços oferecidos por empresas públicas ou privadas (atividades recreativas, esportivas, guiamento).

$\mathrm{Na}$ visão de Eagle, McCool e Haynes (2002) a inserção do turismo em áreas naturais protegidas apresenta contribuição não apenas a dimensão econômica, mas também a proteção ambiental e cultural, bem como, a melhoria da qualidade de vida das comunidades do entorno. Ainda na visão do autor o turismo contribui para proteção, conservação e valorização dos recursos do patrimônio cultural e construído; transmite valores de conservação, através da educação e interpretação; apoia a investigação e o desenvolvimento de boas práticas ambientais; estimula novas empresas de turismo; encoraja o desenvolvimento da cultura, do artesanato e das artes; encoraja as pessoas a aprender as línguas e as culturas dos turistas estrangeiros; no entanto, a inserção do turismo nesses espaços sem um planejamento adequado pode ocorrer também à comercialização das tradições e cultura local, resultando na perda da autencidade e integridade.

Para Pires (2006), os efeitos negativos da visitação em áreas protegidas podem acontecer sobre seus componentes básicos, como água, ar, vegetação, solos, formações rochosas entre outros; e também sobre o ambiente construído pelo homem como sítios arqueológicos, monumentos e construções históricas, sejam por natureza direta, com a presença de pessoas, atividades e comportamentos, ou indireta como a implantação de infraestrutura para servir aos visitantes e turismo. Da mesma forma, é possível inferir que a delimitação destas áreas de proteção integral, como os parques, a permissão do uso por turistas e a cobrança de taxas ou ingressos contribuem para a segregação dos espaços públicos e até mesmo a exclusão 
de parcelas da população e, consequentemente, a potencialização de conflitos sócio territoriais e culturais.

Ruschmann (2001) também cita que um dos efeitos negativos causados pelo turismo de forma mais perceptível relaciona-se geralmente com a construção de infraestruturas, alterando o aspecto físico dos lugares. $E$ sobre isso, Cruz (2001) reforça reconhecendo que esta infraestrutura turística, a construção de meios de hospedagem em áreas não urbanizadas, uma maior circulação de pessoas e todas as outras estruturas associadas representam riscos a desestabilização dos ecossistemas onde está inserido.

Ao que compete aos parques, ações que potencialmente são impactantes de forma negativa estão relacionadas, principalmente, ao volume e a frequência de visitação, bem como, a natureza das atividades que são desenvolvidas. Além disso, existe um aspecto fundamental a ser considerado nesse contexto, que é o grau de sensibilidade e comprometimento dos visitantes com a conservação ambiental (VALLEJO, 2013). Entre os impactos mais comuns derivados das visitações e atividades turísticas nas UC's estão: a compactação do solo ao longo das trilhas; produção de lixo; depredações; pichações; congestionamentos; difusão de hábitos urbanos; a oferta de empregos que normalmente é temporária e não absorve a maioria dos moradores durante baixa temporada; e a perda de autenticidade e integridade quando algumas tradições culturais, quando comercializadas para os turistas.

A WWF aponta que,

[...] tão importante quanto conhecer os atributos e as características "naturais" que justificam a proposição e a criação de uma AP, a partir das perspectivas da Ecologia e disciplinas afins, é conhecer o universo social no qual a AP se projeta como um ator político e institucional de direito próprio. Reconhecendo que a conservação é uma ação de interesse público e que os seus instrumentos desempenham uma função pública - e não estatal -, com a avaliação dos impactos sociais das APs queremos estender a interpelação à(s) sociedade(s) que é(são) afetada(s) de algum modo com a implementação dessa(s) política(s) - do jeito que estas existem hoje e de como gostaríamos que elas fossem num futuro próximo (WWF, 2011, p. 2)

Neste sentido, inúmeros impactos, positivos ou negativos, são possíveis através da criação de unidades de conservação e seu uso público. O Quadro 1 elenca de forma sucinta estes possíveis impactos considerando o uso público destas áreas por visitantes ou turistas. 
Quadro 1: Impactos relacionados à visitação e ao turismo em áreas naturais protegidas.

Chart 1: Impacts related to visitation and tourism in protected areas.

\begin{tabular}{|c|l|}
\hline Dimensão & \multicolumn{1}{c|}{ Impactos } \\
\hline \multirow{5}{*}{ Ambiental } & a)Compactação do solo ao longo das trilhas; \\
& b)Aumento da produção de lixo e uso dos recursos naturais; \\
& c)Perturbação aos ecossistemas, fauna e flora; \\
d)Congestionamentos; & e)Construções de infraestrutura alteram a paisagem; \\
& f)Facilitação do processo de sensibilização ambiental; \\
& g)Agregação de valor ao patrimônio ambiental; \\
& h)Apoia a investigação e o desenvolvimento de boas práticas ambientais \\
& i)Incentivo a criação de áreas de proteção do patrimonio ambiental; \\
& j)Eleva a qualidade de vida das populações. \\
\hline \multirow{5}{*}{ Sociocultural } & a)Aproximação da sociedade e interesse para a conservação da natureza; \\
& b)Possibilidades de recreação e lazer em contato com a natureza; \\
& c)Valorização dos recursos do patrimônio cultural e natural; \\
& d)Encoraja o desenvolvimento da cultura, do artesanato e das artes; \\
& e)Encoraja ao conhecimento de outras culturas e povos; \\
& f)Comercialização das tradições culturais. \\
& g)Depredação do patrimonio ambiental e cultural; \\
& h)Exclusão de populações tradicionais; \\
& i)Geração de conflitos socioterritoriais e culturais. \\
& a)Dinamização da economia local; \\
& b)Contribuição financeira direta com as taxas de entradas dos parques; \\
& c)Criação de empregos e renda; \\
d)Estimula novas empresas; \\
e)Aumento da especulação imobiliária; \\
f)Elevação do custo de vida local; \\
g)Distorções econômicas e modos de produção locais.
\end{tabular}

Fonte: Autoria própria dos autores elaborada com base em Ruschmann, (2010); Vallejo, (2013); Brasil, (2011); Faraji; Aghajani (2010), Pires (2006); Eagles et al. (2002); e WWF (2011).

Source: Authors' own authorship based on Ruschmann, (2010); Vallejo, (2013); Brasil,

(2011); Faraji; Aghajani (2010), Pires (2006); Eagles et al (2002); e WWF (2011).

Dessa forma, é necessário um planejamento adequado para a criação e visitação das unidades de conservação, dentre elas os parques, a fim de que assumam e cumpram as suas funções socioambientais para as quais foram idealizadas e constituídas e na prática cumpram seus papéis de forma efetiva.

\section{Metodologia}

Com o objetivo de avaliar a ideia que se faz sobre os possíveis impactos associados a criação e visitação de UC's, a partir do conceito de Parque disposto em Lei, foi realizada uma pesquisa quantitativa-descritiva baseada na análise com alunos de cursos superiores em turismo do Instituto Federal do Rio Grande do Norte- IFRN, da Universidade Federal do Rio Grande do Norte - UFRN e outros estudantes que cursavam a disciplina de ecoturismo pela UFRN.

A escolha intencional destes alunos ocorreu em detrimento a oportunidade de acesso às salas de aula, por atividades previamente desenvolvidas com eles pelos pesquisadores, e o entendimento da relação 
entre o objeto de análise da pesquisa com a área de conhecimento dos cursos aos quais pertenciam.

A aplicação dos questionários foi realizada no mês de maio de 2017, em sala de aula, com estudantes em três diferentes campi, sendo estes: IFRN-campus Canguaretama/RN (63 respondentes válidos); UFRN- campus Natal (35 respondentes válidos); e o campus Currais Novos da UFRN (13 respondentes válidos). Ressalta-se que a aplicação ocorreu em 1 dia no Campus Canguaretama, 2 dias no Campus Natal, e 2 dias no Campus Currais Novos. Não houve a interlocução pelo pesquisador das perguntas, as quais foram respondidas de forma voluntária e sem identificação.

O total da amostra correspondeu a 111 questionários, considerando que para Hair, Anderson, Tatham e Black (2005, p. 87) "o pesquisador dificilmente realiza uma análise fatorial com uma amostra com menos de 50 observações, e de preferência o tamanho da amostra deve ser maior ou igual a 100".

Desta maneira, utilizou-se uma amostragem não probabilística com estudantes de graduação, aos quais foi solicitado o preenchimento de um questionário em escala métrica de 11 pontos ( 0 a 10), contendo perguntas para a identificação do nível de concordância com as afirmações apresentadas, após a leitura da definição de Parque segundo o SNUC.

Os atributos mensurados na pesquisa foram construídos a partir dos estudos da WWF (2011), que agruparam variáveis capazes de medir os impactos, positivos e negativos, associados à criação e visitação de parques naturais. Assim, foram adotados os 39 atributos apresentados no Quadro 2 (próxima página).

Para análise e tratamentos dos dados utilizou-se o pacote estatístico SPSS 22.0 (Statistical Package for the Social Sciences). Neste, o entendimento do objeto em estudo se dá em razão de uma amostra de pesquisa, sendo possível compreender por meio de elementos mecânicos, fórmulas matemáticas e escalas numéricas, explicações e relações entre variáveis.

Inicialmente, foi feita a análise descritiva a fim de minerar e conhecer os dados obtidos. Os dois coeficientes considerados nesta técnica consideram a estimativa da normalidade de distribuição das variáveis, sendo eles a assimetria e curtose, que segundo Marôco (2010), não devem apresentar valores superiores a 3,0 e 10,0 respectivamente, pois indicariam inadequação do pressuposto da normalidade univariada.

Em seguida, foi realizada a análise fatorial, que consiste em uma técnica que objetiva identificar o conjunto reduzido de variáveis ou fatores, e assim explicar a estrutura correlacional entre um conjunto de variáveis manifestas (MÂROCO, 2010). 
Quadro 2: Atributos e dimensões avaliadas no instrumento.

Chart 2: Attributes and dimensions assessed in the instrument.

\begin{tabular}{|c|c|c|}
\hline Dimensões & Variáveis & Atributos avaliados no instrumento \\
\hline \multirow{4}{*}{ Apoio } & Var. 1 & $\begin{array}{l}\text { A criação de Parques colabora para a promoção de qualidade de } \\
\text { vida; }\end{array}$ \\
\hline & Var. 2 & Com certeza eu visitaria com frequência um Parque natural; \\
\hline & Var. 3 & $\begin{array}{l}\text { A visitação dos Parques colabora para a promoção de qualidade de } \\
\text { vida; }\end{array}$ \\
\hline & Var. 4 & $\begin{array}{l}\text { O governo deveria dar prioridade para a criação de Parques } \\
\text { Naturais. }\end{array}$ \\
\hline \multirow{12}{*}{ Social } & Var. 5 & A exclusão dos residentes da área do Parque; \\
\hline & Var. 6 & $\begin{array}{l}\text { Aumento de estudos, pesquisas e acesso as informações sobre a } \\
\text { área; }\end{array}$ \\
\hline & Var. 7 & Aumentar a criminalidade e violência no entorno do parque; \\
\hline & Var. 8 & Enfraquecimento da identidade cultural dos residentes; \\
\hline & Var.9 & Melhoria da oferta de serviços públicos (saneamento, sáude, etc..); \\
\hline & Var. 10 & Acentuar os conflitos entre grupos sociais (turistas e residentes); \\
\hline & Var. 11 & O incentivo à produção do artesanato local; \\
\hline & Var. 12 & Acentuar conflitos para o uso do território (fundiários); \\
\hline & Var. 13 & Aumento do consumo de drogas e álcool na área e entorno; \\
\hline & Var. 14 & $\begin{array}{l}\text { Fortalecimento das representações locais } \\
\text { cooperativas, ...); }\end{array}$ \\
\hline & Var. 15 & Aumento da prostituição na região; \\
\hline & Var. 16 & Reconhecimento e valorização da cultura local. \\
\hline \multirow{12}{*}{ Ambiental } & Var. 17 & $\begin{array}{l}\text { O aumento da exploração ilegal dos recursos naturais por } \\
\text { residentes, empresas privadas e pelo turismo; }\end{array}$ \\
\hline & Var. 18 & A garantia de acesso aos recursos naturais para futuras gerações; \\
\hline & Var. 19 & Aumento do consumo de energia; \\
\hline & Var. 20 & A manutenção do clima; \\
\hline & Var. 21 & Aumento da produção de lixo; \\
\hline & Var. 22 & A proteção da fauna e flora da área do parque; \\
\hline & Var. 23 & $\begin{array}{l}\text { Aumento da exploração dos recursos naturais em outras áreas não } \\
\text { protegidas legalmente; }\end{array}$ \\
\hline & Var. 24 & A proteção de recursos hídricos; \\
\hline & Var. 25 & Perturbação dos animais, plantas e ecossistemas; \\
\hline & Var. 26 & Manutenção da paisagem do local; \\
\hline & Var. 27 & Aumento da poluição sonora na região; \\
\hline & Var. 28 & Qualidade do ar. \\
\hline \multirow{11}{*}{ Econômica } & Var. 29 & Interesse por novos investimentos no local; \\
\hline & Var. 30 & Especulação imobiliária (elevação do preço da terra e imóveis); \\
\hline & Var. 31 & $\begin{array}{l}\text { Arrecadar recursos financeiros (divisas) através da visitação e } \\
\text { turismo; }\end{array}$ \\
\hline & Var. 32 & $\begin{array}{l}\text { Aumento do preço dos serviços públicos locais (energia, } \\
\text { saneamento); }\end{array}$ \\
\hline & Var. 33 & $\begin{array}{l}\text { Movimentar o comércio local e regional a partir dos visitantes e } \\
\text { turistas; }\end{array}$ \\
\hline & Var. 34 & Aumento da inflação (elevação do custo de vida, alimentos...); \\
\hline & Var. 35 & Aumento de renda a população; \\
\hline & Var. 36 & Aumento de gastos públicos para a manutenção do parque; \\
\hline & Var. 37 & $\begin{array}{l}\text { Criar oportunidades de emprego para os residentes com a } \\
\text { visitação; }\end{array}$ \\
\hline & Var. 38 & Restringe o acesso a área mediante o pagamento de taxa; \\
\hline & Var. 39 & Melhoria de infraestrutura local. \\
\hline
\end{tabular}

Fonte: Elaborado pelos autores com base nos resultados do trabalho da WWF(2011).

Source: Authors' own authorship based in the resultes WWF (2011). 
Para a análise, as variáreis foram agrupadas em 7 dimensões distintas, dentre elas: (1) o apoio à criação e visitação de Parques; os impactos ambientais positivos e negativos (2 e 3); os impactos sociais positivos e negativos (4 e 5) e os impactos econômicos positivos e negativos ( 6 e 7). Assim, buscou-se para cada dimensão a redução dos fatores que explicassem a estrutura correlacional entre as variáveis observadas.

Para tanto, para a redução de variáveis que respondem as dimensões do presente trabalho, optou-se pelo uso do método de análise de componentes principais com rotação Varimax. Para a extração e seleção das variáveis representativas na composição dos fatores foram considerados os coeficientes recomendados por Hair et al. (2005), Corrar; Paulo e Dias (2009) e Mâroco (2010).

Após a redução das variáveis em um único fator dentro de cada dimensão, foi realizada a análise de correlação, para obtenção das variáveis a serem correlacionadas. Para análise de correlação entre apoio e os impactos utilizou-se o coeficiente de Pearson, confirmada também pelo coeficiente de Spearman.

\section{Resultados e Discussão}

Inicialmente, para construção dos resultados foram analisadas as 39 variáveis que fizeram parte das dimensões. Dessa forma, realizou-se uma análise descritiva dos dados com observação principalmente nas estatísticas referentes à assimetria e a curtose discutidas anteriormente. Desta forma, baseando-se nos critérios definidos por Mâroco (2010), todas as variáveis encontraram-se com distribuição normal, já que os valores de assimetria não ultrapassaram 3 e curtose 10.

$\mathrm{Na}$ análise fatorial foram selecionadas as variáveis seguindo os critérios de: Cargas fatoriais próximas a 0,50 ou superiores; Anti-imagem (MSA) com valor acima de 0,50; Comunalidade com valor superior a 0,50 ; Eigenvalue acima de 1,0; Variância total acumulada superior a 60\%; e o Alpha de Cronbach $(\alpha)$ acima de 0,70, conforme critérios recomendados por Hair et. al. (2005), Corrar, Paulo e Dias (2009) e Mâroco (2010).

Os resultados obitdos estão na Tabela 1. Como podem ser observados, com exceção do Alpha de Cronbach $(\alpha)$ da dimensão Ambiental Positivo, os critérios da análise fatorial exploratória foram atendidos, encontram-se adequados e em conformidade com a técnica. O Alpha de Cronbach da dimensão Ambiental Positivo teve o valor abaixo do que é sugerido, fato que pode ser explicado porque esta dimensão possui apenas duas variáveis, o que pode influenciar no valor do Alpha, ainda assim, esta situação não viola gravemente a investigação e dessa forma a análise fatorial exploratória encontra-se satisfatória para a proposta. 
Tabela 1 - Análise fatorial para as dimensões: apoio, impactos ambientais, sociais e econômicos, positivos e negativos.

Table 1: Factor analysis for the dimensions: support, environmental, social and economic impacts, positive and negative.

\begin{tabular}{|c|c|c|c|c|c|c|}
\hline Dimensão & $\begin{array}{l}\text { Carga } \\
\text { fatorial }\end{array}$ & $\begin{array}{c}\text { Anti- } \\
\text { imagem } \\
\text { (MSA) }\end{array}$ & Comunalidade & Eigenvalue & $\begin{array}{c}\text { Variância } \\
(\%)\end{array}$ & $\alpha$ \\
\hline Apoio & & & & 1,967 & $65,57 \%$ & 0,725 \\
\hline $\begin{array}{l}\text { Var.1-A criação de } \\
\text { parques colabora para a } \\
\text { promoção de qualidade } \\
\text { de vida; }\end{array}$ & 0,82 & 0,65 & 0,67 & & & \\
\hline $\begin{array}{l}\text { Var.2- Com certeza eu } \\
\text { visitaria com frequência } \\
\text { um Parque Natural; }\end{array}$ & 0,75 & 0,74 & 0,56 & & & \\
\hline $\begin{array}{l}\text { Var.3- A visitação dos } \\
\text { parques colabora para a } \\
\text { promoção de qualidade } \\
\text { de vida; }\end{array}$ & 0,85 & 0,62 & 0,72 & & & \\
\hline Ambiental Positivo & & & & 1,395 & $69,73 \%$ & 0,561 \\
\hline $\begin{array}{l}\text { Var.20-A manutenção do } \\
\text { clima; }\end{array}$ & 0,83 & 0,50 & 0,69 & & & \\
\hline Var.28-Qualidade do ar; & 0,83 & 0,50 & 0,69 & & & \\
\hline Ambiental Negativo & & & & 2,123 & $70,77 \%$ & 0,793 \\
\hline $\begin{array}{l}\text { Var.21-Aumento da } \\
\text { produção de lixo; }\end{array}$ & 0,81 & 0,73 & 0,67 & & & \\
\hline $\begin{array}{l}\text { Var.25-Pertubação dos } \\
\text { animais, plantas e } \\
\text { ecossistemas; }\end{array}$ & 0,83 & 0,70 & 0,70 & & & \\
\hline $\begin{array}{l}\text { Var.27-Aumento da } \\
\text { poluição sonora na } \\
\text { região; }\end{array}$ & 0,86 & 0,66 & 0,75 & & & \\
\hline Social Positivo & & & & 2,087 & $69,57 \%$ & 0,781 \\
\hline $\begin{array}{l}\text { Var.11-O incentivo à } \\
\text { produção do artesanato } \\
\text { local; }\end{array}$ & 0,85 & 0,66 & 0,73 & & & \\
\hline $\begin{array}{l}\text { Var.14-Fortalecimento } \\
\text { das representações } \\
\text { locais; }\end{array}$ & 0,82 & 0,70 & 0,68 & & & \\
\hline $\begin{array}{l}\text { Var.16-Reconhecimento } \\
\text { e valorização da cultura } \\
\text { local; }\end{array}$ & 0,81 & 0,72 & 0,66 & & & \\
\hline Social Negativo & & & & 2,166 & $72,20 \%$ & 0,804 \\
\hline $\begin{array}{l}\text { Var.7-Aumentar a } \\
\text { criminalidade e violência } \\
\text { no entorno do parque; }\end{array}$ & 0,79 & 0,74 & 0,63 & & & \\
\hline $\begin{array}{l}\text { Var.13-Aumento do } \\
\text { consumo de drogas e } \\
\text { álcool na área e entorno; }\end{array}$ & 0,90 & 0,61 & 0,81 & & & \\
\hline $\begin{array}{l}\text { Var.15-Aumento da } \\
\text { prostituição na região; }\end{array}$ & 0,84 & 0,66 & 0,71 & & & \\
\hline
\end{tabular}

Continua... 
...continuação.

\begin{tabular}{|c|c|c|c|c|c|c|}
\hline Dimensão & $\begin{array}{l}\text { Carga } \\
\text { fatorial }\end{array}$ & $\begin{array}{c}\text { Anti- } \\
\text { imagem } \\
\text { (MSA) }\end{array}$ & Comunalidade & Eigenvalue & $\begin{array}{c}\text { Variância } \\
(\%)\end{array}$ & $\alpha$ \\
\hline Econômico Positivo & & & & 1,919 & $63,97 \%$ & 0,718 \\
\hline $\begin{array}{l}\text { Var.31-Arrecadar } \\
\text { recursos financeiros } \\
\text { através da visitação e } \\
\text { turismo; }\end{array}$ & 0,85 & 0,61 & 0,72 & & & \\
\hline $\begin{array}{l}\text { Var.33-Movimentar o } \\
\text { comércio local e regional } \\
\text { a partir dos visitantes e } \\
\text { turistas; }\end{array}$ & 0,77 & 0,67 & 0,60 & & & \\
\hline $\begin{array}{l}\text { Var.37-Criar } \\
\text { oportunidades de } \\
\text { emprego para os } \\
\text { residentes com a } \\
\text { visitação; }\end{array}$ & 0,76 & 0,68 & 0,58 & & & \\
\hline Econômico Negativo & & & & 1,940 & $64,66 \%$ & $\overline{0,724}$ \\
\hline $\begin{array}{l}\text { Var.30- Especulação } \\
\text { imobiliária; }\end{array}$ & 0,81 & 0,66 & 0,66 & & & \\
\hline $\begin{array}{l}\text { Var.32-Aumento do } \\
\text { preço dos serviços } \\
\text { públicos locais; }\end{array}$ & 0,81 & 0,67 & 0,66 & & & \\
\hline $\begin{array}{l}\text { Var.38- Restringe o } \\
\text { acesso a área mediante } \\
\text { o pagamento de taxa; }\end{array}$ & 0,78 & 0,70 & 0,61 & & & \\
\hline
\end{tabular}

$\alpha$ : Alpha de Cronbach. Fonte: Resultados da pesquisa. Source: Search results

Em relação à dimensão apoio foi possível observar que a ideia sobre os parques se associa à promoção de qualidade de vida e que a visitação destas áreas é algo desejado (Var. 1, 2 e 3) o que vai de encontro com as ideias de Eagle, McCool e Haynes (2002). Porém, percebe-se que a criação destes espaços não foi tratada como prioridade de políticas públicas. Este resultado aponta que, embora a conservação dos recursos naturais seja em parte compreendida como importante ação, parece estar ainda desintegrada de um conceito mais abrangente sobre qualidade de vida.

Guimarães e Pellin (2015) ressaltam que além dos recursos naturais fornecerem os serviços ecossistêmicos, a sua preservação agrega valores estéticos e culturais e ajuda a evitar riscos ambientais sofridos pela falta de ordenamento urbano. Neste sentido, é importante a formulação e execução de políticas que garantam espaços para a proteção da natureza no tecido urbano e facilitem o seu acesso da população a estas áreas. Talvez, o conceito de parque utilizado na legislação brasileira ainda não seja suficiente para uma compreensão mais holística e abrangente do valor socioambiental e cultural destas áreas.

Considerando as variáveis que compuseram as dimensões dos impactos ambientais positivos, foi possível observar que os parques admitem uma importância na garantia de um ambiente mais agradável (Var. 20 e 28), provavelmente, associado à ideia de área verde conforme apontado por Faraji e Aghajani (2006), porém, não incluiu aspectos relevantes do processo de 
manutenção do equilíbrio ecológico e acesso a gerações futuras. Cabe ressaltar que esta foi a única dimensão onde apenas dois atributos mostraram-se significativos na composição do fator, sugerindo talvez uma adequação na construção das assertivas.

Em relação aos impactos ambientais negativos, os atributos significativos (Var. 21, 25 e 27) parecem associar-se mais à visitação, uma vez que estes impactos são claramente relacionados às ações antrópicas como afirmado por Pires (2006). Neste sentido, o resultado colabora com a necessidade de elaboração de Planos de Uso Público conforme previstos em lei, a fim de minimizar estes efeitos das visitações contribuindo para a gestão adequada destes recursos naturais (BRASIL, 2000).

Constituindo a dimensão de impactos sociais positivos, ganharam destaque aspectos relacionados à valorização cultural e ao fortalecimento das representações locais (Var. 11, 14 e 16), colaborando com a visão de que os parques também assumem funções estéticas, culturais, educacionais e recreativas, através de seus programas de uso público, equipamentos e serviços tal como evidenciado por Eagle, McCool e Haynes (2002). Em especial, os parques protegidos em áreas urbanas são vistos como importante locus do antagonismo de forças existentes fazendo parte da construção da luta pelo direito à cidade. (PACHECO; RAIMUNDO, 2014).

Já a dimensão dos impactos sociais negativos demonstrou-se associada a aspectos do aumento de criminalidade, violência e prostituição (Var. 7, 13 e 15), provavelmente em detrimento a perspectiva de visitação e possível processo de segregação territorial assim como assegurado por Pires (2006). Importante ressaltar que, segundo os resultados, a concepção de parque como espaço que permite a desapropriação particular e, portanto, a exclusão de residentes dentro de sua área e os possíveis conflitos que isto pode gerar, não se apresentou significativo aos respondentes. Acredita-se que os resultados podem apresentar-se de maneira diferente quando 0 público representar a população que diretamente é interferida com a delimitação da área de parque, os residentes dela ou de seu entorno.

Quanto aos impactos positivos econômicos foram significativas as assertivas sobre geração de divisas, emprego e, consequentemente, movimentação comercial através da visitação destas áreas (Var.31, 33 e 37) como exposto por Faraji e Aghajani (2006). Neste sentido, é possível inferir que os parques ganham economicamente destaque quando associados a oportunidades de comercialização de produtos e serviços para atender a um público visitante, não podendo restringir-se apenas a uma área de proteção de recursos naturais.

Os impactos econômicos negativos se mostraram associados à especulação imobiliária, aumento do preço dos serviços públicos no local e ao pagamento de taxa para uso de um bem público (Var. 30, 32 e 38) como relatado por Ruschmann (2001). Os resultados demonstram que os parques estão associados a uma possível elevação dos custos de vida, os quais podem acontecer apenas em detrimento da criação da UC. Neste contexto, se torna relevante refletir a questão de segregação espacial sujeita a estas áreas 
e o papel social que podem exercer, a fim de configurá-las nos espaços democráticos aos quais se propõem.

Por fim, ao correlacionar o apoio à criação e visitação dos parques naturais protegidos aos impactos ambientais, sociais e econômicos, observou-se significância moderada apenas nos impactos positivos, conforme descrito na Tabela 2.

Tabela 2: Coeficientes de Correlação de Pearson e Spearman.

Table 2: Coefficients of correlation of Pearson e Speaman

\begin{tabular}{|c|c|c|c|c|}
\hline \multirow[b]{2}{*}{ IMPACTOS } & \multicolumn{4}{|c|}{ APOIO } \\
\hline & Pearson & Sig. (2 ext) & Spearman & Sig. (2 ext) \\
\hline Amb. Pos. &, $216^{*}$ & 0,022 & $246^{* *}$ & 0,009 \\
\hline Amb. Neg. & $-0,049$ & 0,61 & $-0,028$ & 0,772 \\
\hline Soc. Pos. & $289^{* *}$ & 0,002 &, $336^{* *}$ & 0 \\
\hline Soc. Neg. & 0,146 & 0,137 & 0,085 & 0,387 \\
\hline Eco.Pos. &, $322^{* *}$ & 0,001 &, $356^{* *}$ & 0 \\
\hline Eco.Neg. & 0,045 & 0,644 & 0,106 & 0,271 \\
\hline
\end{tabular}

Fonte: Resultados da pesquisa.

Source: Search results.

Assim, os resultados demonstram que a ideia de que a criação e visitação de parques naturais são aceitas e apoiadas, uma vez que se associam as possibilidades de geração de impactos ambientais, sociais e econômicos positivos.

Estudos norte-americanos tais como, Public Opinion on National Parks (HART RESEARCH, 2016) e Strong Bipartisan Support for National Parks ( Hart Research \& North Star Opinion Research, 2012), também apontam esta relação positiva entre a criação de áreas protegidas e o apoio do público em geral. Entretanto algumas pesquisas também demonstram a ocorrência de pensamentos divergentes, principalmente quando o público participante corresponde às comunidades que vivem dentro ou no entorno destas áreas de países pobres e em desenvolvimento, as quais dependem diretamente da exploração de seus recursos naturais. Neste caso, a visão sobre a criação de parques naturais e a visitação turística não é essencialmente positiva e vem associada aos impactos negativos e a uma série de conflitos (BENNETT; DEARDEN, 2014; WWF, 2011; KIDEGHESHO, RØSKAFT; KALTENBORN, 2007; LUNDMARK, FREDMAN; SANDELL, 2010).

Convém ressaltar que os respondentes participantes desta pesquisa não representaram, em sua maioria, pessoas diretamente envolvidas com a criação dos parques, mas sim, visitantes reais ou potenciais destas áreas, fato que sugere resultados diferenciados para a mesma pesquisa direcionada a outros públicos como residentes, turistas ou gestores destes espaços. 


\section{Considerações finais}

A compreensão do imaginário sobre criação e visitação em unidades de conservação, especificamente pertencente a categoria de Parques Nacionais, traz contribuições no sentido de apresentar possíveis interpretações de diferentes atores quanto as contribuições dessas áreas nas dimensões ambiental, social e econômica.

Os resultados da pesquisa demonstraram um significativo apoio à criação de parques naturais protegidos pelo público de estudantes, reais e potenciais visitantes destas áreas, o qual mostrou relação com os possíveis impactos positivos ambientais, sociais e econômicos.

A análise fatorial das dimensões propostas permitiu inferir que na percepção de alunos de graduação de cursos de turismo no estado do Rio grande do Norte existe uma aceitação à criação e visitação de UC's, como os parques, apoiada pelo reconhecimento dos impactos positivos associados a elas e seu uso público.

$\mathrm{Na}$ construção da dimensão apoio fatores que associaram os parques na promoção da qualidade de vida foram relevantes e os respondentes demonstraram interesse na visitação das áreas. Na composição das demais dimensões associadas aos impactos positivos observou-se a contribuição dos parques para manutenção de clima e qualidade do ar, valorização cultural e fortalecimento das representações locais e potencial gerador de divisas, emprego e outras oportunidades comerciais.

Quanto aos impactos negativos, os fatores significativos que compuseram as dimensões relacionaram a criação e visitação dos parques com o possível aumento da poluição, produção de lixo e perturbação da fauna e flora; criminalidade, violência e prostituição para as áreas e aumento dos preços imobiliários e de produtos e serviços.

Embora a criação e visitação destas UC's foi interpretada de maneira positiva, os participantes não as apresentaram como prioridade de políticas públicas. Assim, torna-se importante refletir sobre o real papel destas áreas quando são associadas à promoção de qualidade de vida, uma vez que a interpretação das mesmas partiu do contexto conceitual jurídico de sua representação e nem todos os respondentes devidamente conhecem seus contextos de criação e uso público.

Considera-se ainda, que a demanda entrevistada se refere a estudantes do ensino superior em Turismo, que, provavelmente, não são pessoas que se encontram em comunidades do entorno de UCs. Sendo assim, sugere-se futuras pesquisas com aplicação de instrumentos com residentes e gestores dessas áreas, sabendo que, possivelmente, os resultados poderão apresentar novas considerações sob outra ótica.

Acredita-se que o papel fundamental dos parques naturais protegidos é a promoção da qualidade de vida às populações. Porém, a sua função ambiental, social e econômica só será efetiva a partir de trabalhos de sensibilização e educação ambiental, uma vez que a proteção jurídica por si só não é suficiente para impedir muitos impactos provocados pelo 
desconhecimento das necessidades de conservação e das práticas adequadas de uso destes ambientes.

\section{Referências}

BENNETT, N.J.; DEARDEN, P. Why local people do not support conservation: Community perceptions of marine protected area livelihood impacts, governance and management in Thailand. Marine Policy, Elsevier, vol. 44(C), p.107-116 2014.

BRASIL. Lei no 9.985, de 18 de julho de 2000. Regulamenta o art. 225, § 10, incisos I, II, III e VII da Constituição Federal, institui o Sistema Nacional de Unidades de Conservação da Natureza e dá outras providências. Disponível em: $<$ http://www.mma.gov.br/port/conama/legiabre.cfm?codlegi=322> Acesso em: 10 de julho de 2017.

BRASIL. Diretrizes para visitação em Unidades de Conservação. Diretoria de áreas protegidas. Brasília: Ministério do Meio Ambiente, 2006a.

BRASIL. Projeto Orla: Fundamentos para gestão integrada. Brasília: Ministério do Meio Ambiente, 2006b.

BRASIL. Ecoturismo: Orientações básicas. Brasília: Ministério do Turismo, 2010.

BRASIL. Sistema Nacional de Unidades de Conservação da Natureza: Lei oㅜ 9.985, de 18 de julho de 2000; Decreto no 4.340, de 22 de agosto de 2002; Decreto no 5.746, de 5 de abril de 2006. Plano Estratégico Nacional de Áreas Protegidas: Decreto № 5.758, de 13 de abril de 2006 / Ministério do Meio Ambiente. Brasília: MMA/SBF, 2011.

BRASIL. Ministério do Turismo. Plano nacional do Turismo. 2011b. Disponível em <http://www.turismo.gov.br/images/conselhos/conselho nacional/documentos conselho/Apresentacao Mtur PNT em acao parques naturais.pdf> Acesso em: 07 Maio de 2017.

BRASIL. Ministério do Meio Ambiente. Visitação em parques nacionais sobe 238\%. 2016. Disponível em <http://www.mma.gov.br/informma/item/13228noticia-acom-2016-02-1427.html> Acesso em: 07 Maio de 2017.

BRITO, M C.W. Unidades de Conservação: intenções e resultados. São Paulo: Anablume, 2000.

CORRAR, L.J; PAULO, E.; DIAS FILHO, J.M. Análise Multivariada: para os cursos de administração, ciências contábeis e economia. São Paulo: Atlas. 2009.

CRUZ, R.C.A. (2001). Introdução à Geografia do Turismo. São Paulo: Roca.

DIEGUES, A.C. O Mito Moderno da Natureza Intocada. São Paulo: Hucitec, 2000.

DOUROJEANNI, M. Sobre a origem do termo unidade de conservação, 2015. Artigo no Jornal O ECO. Associação o Eco. Disponível em < http://www.oeco.org.br/colunas/marc-dourojeanni/28858-sobre-a-origem-dotermo-unidade-de-conservacao/> Acesso em: 10 de maio de 2017.

EAGLES, P.F.; MCCOOL, S.F.; HAYNES, C.D. Sustainable Tourism in Protected Areas: Guidelines for Planning and Management. Cambridge: IUCN Gland 2002. 
FARAJI, A.; AGHAJANI, S. The Relationship between Tourism and Environment. Iranian Journal of Tourism \& Hospitality, v., n.1, p.37-48, 2010.

GUIMARÃES, E.; PELLIN, A. BiodiverCidade: desafios e oportunidades na gestão de áreas protegidas urbanas. São Paulo: Matrix, 2015.

HAIR, J.; ANDERSON, R.; TATHAM, R.; BLACK, W. (2005). Análise Multivariada de dados. Porto Alegre: Bookman, 2005.

HART RESEARCH. Environmental Protection Survey. 2016. Disponível em $<$ https://cdn.americanprogress.org/wp-

content/uploads/2016/04/11070242/CAP Polling-Slide-Deck-National-

Parks2.pdf > Acesso em: 02 de Agosto de 2018.

HART RESEARCH. NORTH STAR OPINION RESEARCH. Strong Bipartisan Support for National Parks. $2012 . \quad$ Disponível em: $<$ https://www.corpsnetwork.org/sites/default/images/advocacy/Strong-BipartisanSupport-For-National-Parks.pdf > Acesso em: 02 de Agosto de 2018.

KIDEGHESHO, J.R.; RØSKAFT, E.; KALTENBORN, B.P. Factors influencing conservation attitudes of local people in Western Serengeti, Tanzania. Biodiversity and Conservation, v.16, Issue 7, pp 2213-2230, 2007.

LEUZINGER, M.D. Uso Público em Unidades de Conservação. In: Anais do Congresso de Direito Ambiental - PUC-RIO, 2010, Rio de Janeiro, 2010.

LUNDMARK, L.; FREDMAN, P.; SANDELL, K. National parks and protected areas and the role for employment in tourism and forest sectors: a Swedish case. Ecology and Society, v.15, n.1, art.19, 2010.

MARÔCO, J. Análise de equações estruturais: fundamentos teóricos, software e aplicações. Perô Pinheiro: Report Number, 2010.

OLIVEIRA, E.S. Impactos socioambientais e econômicos do turismo e suas repercussões no desenvolvimento local: o caso de Itacaré -Bahia. Dissertação de Mestrado. UESC/Ilhéus: UFBA, 2008.

PACHECO, R.T.B.; RAIMUNDO, S. Parques urbanos e o campo dos estudos do lazer. Revista Brasileira de Estudos do Lazer, v.1, n.3, p.43-66, 2014.

PIRES, P. As Múltiplas Facetas e Implicações da Relação Turismo e Meio Ambiente. Anais do IV SeminTUR - Seminário de Pesquisa em Turismo do MERCOSUL, 2006.

PUREZA, F.; PELLIN, A.; PADUA, C. Unidades de Conservação: Fatos e personagens que fizeram a história das categorias de manejo. São Paulo: Matrix, 2015.

ROCHA, L.G.M. Os Parques Nacionais do Brasil e a Questão Fundiária: o caso do Parque Nacional da Serra dos Órgãos. Dissertação de Mestrado. Programa de Pós-Graduação em Ciência Ambiental da Universidade Federal Fluminense. Rio de Janeiro, 2002.

ROCHA, L.G.M.; DRUMMOND, J.A.; GANEM, R.S. Parques Nacionais Brasileiros: problemas fundiários e alternativas para sua resolução. Revista de Sociologia e Política, Curitiba, v.18, n.36, p.205-226, 2010.

RUCHMANN, D.V.R. Turismo e planejamento sustentável: a proteção do meio ambiente. São Paulo: Papirus, 2001. 
ROCKTAESCHEL, B.M. Terceirização em áreas protegidas: estímulo ao ecoturismo no Brasil. São Paulo: Senac, 2006.

VALLEJO, L.R. Uso público em áreas protegidas: atores, impactos, diretrizes de planejamento e gestão. Anais - Uso Público em Unidades de Conservação. Universidade Federal Fluminense, 2013.

VALLEJO, L.R. Unidade de Conservação: Uma Discussão Teórica á Luz dos Conceitos de Território e Políticas Públicas. GEOgraphia, Universidade Federal Fluminense, v.4, n.8, p.57-78, 2002.

WWF. Avaliação de impactos sociais de áreas protegidas no Brasil: caminhos e desafios. 2011. Disponível em <http://d3nehc6yl9qzo4.cloudfront.net/downloads/livro seminario avaliacao web. pdf. $>$ Acesso em: 15 de janeiro de 2017.

Paula Normandia Brumatti: Universidade Federal do Rio Grande do Norte, Natal, RN, Brasil.

E-mail: paulanmb@yahoo.com.br

Link para o currículo Lattes: http://lattes.cnpq.br/8162160743491260

Carla Medeiros Santana: Universidade Federal do Rio Grande do Norte, Natal, RN, Brasil.

E-mail: carlastefaniasantana@yahoo.com.br

Link para o currículo Lattes: http://lattes.cnpq.br/0018480906444662

Fernanda Raphaela Dantas: Universidade Federal do Rio Grande do Norte, Natal, RN, Brasil.

E-mail: nandaraphaela@hotmail.com

Link para o currículo Lattes: http://lattes.cnpq.br/5037254795248546

Sérgio Marques Junior: Universidade Federal do Rio Grande do Norte, Natal, RN, Brasil.

E-mail: sergio@ct.ufrn.br

Link para o currículo Lattes: http://lattes.cnpq.br/3095760811566254

Data de submissão: 30 de agosto de 2018

Data de recebimento de correções: 31 de outubro de 2018

Data do aceite: 31 de outubro de 2018

Avaliado anonimamente 